\title{
Weight gain in pregnancy and risk of maternal hyperglycemia
}

\author{
Sharon J. Herring, MD, MPH, Emily Oken, MD, MPH, Sheryl L. Rifas-Shiman, MPH, Janet W. \\ Rich-Edwards, ScD, Alison M. Stuebe, MD, MSc, Ken P. Kleinman, ScD, and Matthew W. \\ Gillman, MD, SM \\ Center for Obesity Research and Education (Dr Herring), Temple University School of Medicine, \\ Philadelphia, PA; the Obesity Prevention Program, Department of Ambulatory Care and \\ Prevention (Drs Oken, Kleinman, and Gillman and Ms Rifas-Shiman), Harvard Medical School \\ and Harvard Pilgrim Health Care, Boston, MA; the Connors Center for Women's Health and \\ Gender Biology (Dr Rich-Edwards), Brigham and Women's Hospital, Boston, MA; the Division of \\ Maternal-Fetal Medicine, Department of Obstetrics and Gynecology (Dr Stuebe), University of \\ North Carolina School of Medicine, Chapel Hill, NC; and the Department of Nutrition (Dr Gillman), \\ Harvard School of Public Health, Boston, MA.
}

\begin{abstract}
OBJECTIVE-The purpose of this study was to examine associations of weight gain from prepregnancy to glycemic screening with glucose tolerance status.

STUDY DESIGN-Main outcomes were failed glycemic screening (1-hour glucose result $\geq 140$ $\mathrm{mg} / \mathrm{dL}$ ) with either 1 high value on 3-hour oral glucose tolerance testing (impaired glucose tolerance in pregnancy) or $\geq 2$ high values on 3-hour oral glucose tolerance testing (gestational diabetes mellitus). We performed multinomial logistic regression to determine the odds of these glucose intolerance outcomes by quartile of gestational weight gain among 1960 women in Project Viva.
\end{abstract}

RESULTS-Mean gestational weight gain was $10.2 \pm 4.3$ (SD) kg. Compared with the lowest quartile of weight gain, participants in the highest quartile had an increased odds of impaired glucose tolerance in pregnancy (adjusted odds ratio, 2.54; 95\% confidence interval, 1.25-5.15), but not gestational diabetes mellitus (odds ratio, 0.93 ; 95\% confidence interval, $0.50-1.70$ ).

CONCLUSION-Higher weight gain predicted impaired glucose tolerance in pregnancy, but not gestational diabetes mellitus.

\section{Keywords}

gestational diabetes mellitus; impaired glucose tolerance; obesity; pregnancy; weight gain

\footnotetext{
(C) 2009 Mosby, Inc. All rights reserved.

Reprints: Sharon J. Herring, MD, MPH, Center for Obesity Research and Education, Temple University School of Medicine, 3223 N. Broad St., Suite 175, Philadelphia, PA 19140. Sharon_Herring@post.harvard.edu.

Presented at the Annual Scientific Meeting of the Society for Pediatric and Perinatal Epidemiologic Research, Chicago, IL, June 2324, 2008.
} 
Gestational diabetes mellitus (GDM) complicates $1-14 \%$ of pregnancies $^{1}$ and is associated with increased risk of adverse perinatal outcomes ${ }^{1-5}$ as well as longer-term complications of obesity and type 2 diabetes mellitus in both mothers and children. ${ }^{2,3,6-8}$ Maternal hyperglycemia less severe than that used to define overt diabetes mellitus is also related to perinatal complications. ${ }^{8-12}$ These effects may be reduced through treatment. ${ }^{13}$ Given the rise in GDM incidence over the past decade, ${ }^{14}$ research to identify modifiable determinants of glucose intolerance has become a public health priority.

Pregravid obesity is the most well-documented modifiable risk factor for GDM. ${ }^{15,16}$ Several studies additionally suggest that the risk of glucose intolerance increases with weight gain just prior to pregnancy. ${ }^{16-19}$ Although the exact mechanisms by which weight gain and obesity promote incident diabetes mellitus are not understood fully, a combination of adiposity-generated insulin resistance and deterioration in pancreatic beta cell function are likely to blame. ${ }^{20-22}$ Given that fat comprises approximately $30 \%$ of weight gain in pregnancy, ${ }^{23-25}$ during which time women experience physiologic reductions in insulin sensitivity, ${ }^{26}$ it seems plausible that greater gestational weight gain would also increase the risk of GDM.

Limited data exist regarding the relationship between gestational weight gain and maternal hyperglycemia. Saldana $\mathrm{et}^{\mathrm{al}^{27}}$ found no association between total weight gain and glucose tolerance until the end of the second trimester; however, when the authors analyzed gestational weight gain as a ratio of actual gain compared with recommended gain, they found a modestly increased risk of impaired glucose tolerance (IGT) in pregnancy solely in overweight women, but no association with GDM. A more recent trial revealed 20\% reductions in serum insulin and leptin levels at 27 weeks of gestation among obese women who were assigned randomly to restrict weight gain during pregnancy compared with control subjects; however, the small sample size precluded the authors' ability to make conclusions about risk of incident GDM. ${ }^{28}$

To clarify the relationship between gestational weight gain and maternal hyperglycemia, we used data from a longitudinal cohort study of pregnant women. We evaluated associations of both total gestational weight gain before glycemic screening and trimester-specific weekly rate of gain with glucose tolerance status.

\section{Materials and Methods}

\section{Study population and design}

Study subjects were recruited into Project Viva at their first prenatal visit from 1 of 8 urban and suburban obstetric offices that were associated with a multispecialty group practice in eastern Massachusetts from 1999-2002, as summarized previously. ${ }^{29,30}$ Eligibility criteria included fluency in English, gestational age of $<22$ weeks, and a singleton pregnancy. All mothers provided written informed consent, and all procedures were in accordance with ethical standards for human experimentation. ${ }^{31}$ Institutional review boards of the participating sites approved the study. 
Of the 2128 women who delivered a live singleton infant, 81 women had a body mass index $(\mathrm{BMI})<18.5 \mathrm{~kg} / \mathrm{m}^{2}$ (underweight) and were excluded, because they are at low risk for glucose intolerance and only 2 underweight participants had GDM in our cohort. We also excluded women who had a history of type 1 or type 2 diabetes mellitus $(n=16)$, who were missing information on prepregnancy diabetes status $(n=22)$ or BMI $(n=7)$, or who had incomplete data on glucose tolerance testing $(n=17)$ or weight gain $(n=25)$ in pregnancy, which left 1960 women in this analysis. Women who were not included were somewhat younger ( 30.5 vs 31.9 years old), less likely to be white (53\% vs $67 \%$ ), and less likely to be of normal weight ( $46 \%$ vs $61 \%$ ), but did not differ in mean glucose level at glycemic screening or GDM in the index pregnancy.

\section{Gestational weight gain}

We calculated total gestational weight gain before second-trimester glycemic screening as the difference between the weight that was recorded at the glycemic screen and self-reported prepregnancy weight. If no measure of weight was available at the time of glycemic screening, we used linear interpolation between the 2 surrounding weights to estimate the weight on that day. Additionally, we computed the rate of weight gain per week from prepregnancy to 13 weeks (91 days) gestation, and from 13 weeks of gestation to glycemic screening. We used linear interpolation to estimate the weight at 13 weeks of gestation if it was not available from the obstetric record.

We previously reported findings from a validation study in our cohort that compared selfreported prepregnancy weights with clinically measured weights among a sample of 170 women who had weight recorded in the medical record within 3 months before their last menstrual period. We found that the relationship between the 2 weights was linear and tightly correlated $(r=0.99)$, with a mean systematic underreport of $1 \mathrm{~kg}$ that did not vary by maternal race/ethnicity, gestational age at enrollment into the study, or weight itself. ${ }^{29}$

\section{Glycemic screening and classification of glucose tolerance status}

Participating women underwent routine glycemic screening for GDM between 26-28 weeks of gestation with a nonfasting oral glucose challenge test (GCT), in which venous blood was sampled 1 hour after a 50-g oral glucose load. If the 1 -hour glucose result was $\geq 140 \mathrm{mg} / \mathrm{dL}$, the participant was referred for a 100-g fasting glucose 3-hour tolerance test (OGTT).

Normal OGTT results were a blood glucose level of $<95 \mathrm{mg} / \mathrm{dL}$ at baseline, $<180 \mathrm{mg} / \mathrm{dL}$ at 1 hour, $<155 \mathrm{mg} / \mathrm{dL}$ at 2 hours, and $<140 \mathrm{mg} / \mathrm{dL}$ at 3 hours. ${ }^{1}$

Based on a combination of the GCT and OGTT results, we focused on 2 categories of glucose intolerance: (1) IGT in pregnancy was defined as failing the GCT (1-hour glucose result of $\geq 140 \mathrm{mg} / \mathrm{dL}$ ) with 1 high value on the 3-hour OGTT, and (2) GDM was defined as failing the GCT (1-hour glucose result of $\geq 140 \mathrm{mg} / \mathrm{dL}$ ) with $\geq 2$ high values on the 3-hour OGTT. We chose these definitions of glucose intolerance to allow for comparison with previously published work. ${ }^{27}$ Women whose GCT results were $<140 \mathrm{mg} / \mathrm{dL}$ did not have OGTT testing and comprised the referent group (normal glucose tolerance [NGT]). We also evaluated the remaining mothers who had GCT results of $\geq 140 \mathrm{mg} / \mathrm{dL}$, but no high values on the OGTT, separately from mothers with NGT results (which differs from the work of 
Saldana et $\mathrm{al}^{27}$ ), because data are mixed regarding differences in outcomes for this group vs NGT or IGT in pregnancy. $8,32,33$

\section{Assessment of covariates}

Using a combination of interviews and questionnaires at the first study visit ( $~ 10$ weeks of gestation), we collected information on maternal race/ethnicity, age, parity, history of GDM in a previous pregnancy, history of diabetes mellitus in the participant's own mother, and smoking habits. We calculated BMI $\left(\mathrm{kg} / \mathrm{m}^{2}\right)$ from self-reported prepregnancy height and weight and categorized women as either normal weight $\left(18.5-24.9 \mathrm{~kg} / \mathrm{m}^{2}\right)$, overweight $\left(25.0-29.9 \mathrm{~kg} / \mathrm{m}^{2}\right)$, or obese $\left(\geq 30 \mathrm{~kg} / \mathrm{m}^{2}\right) .{ }^{34}$ Gestational age at glycemic screening was calculated as the difference between the date of a woman's GCT result and her last menstrual period (adjusted to reflect gestational age that had been calculated by secondtrimester ultrasound examination, if the 2 estimates differed by $>10$ days). As part of the early pregnancy questionnaire, participants also reported their physical activity habits during the 12 months before pregnancy. Vigorous activity was of primary interest because results from Project Viva have shown reductions in risk of both GDM and excessive gestational weight gain among women who perform any vigorous activity before pregnancy. ${ }^{35,36} \mathrm{In}$ mid pregnancy, we assessed diet, time spent watching television, and early pregnancy leisuretime physical activity by questionnaire; however, we did not include dietary factors or television-viewing behavior in the present analysis because neither was associated with glucose tolerance in this cohort. 35,37

\section{Statistical analysis}

Because we found moderate variation among participants in timing of glycemic screening (mean, 27.7 weeks; range, 9.3-38.0 weeks), we used a linear regression model to compute our weight gain variable that was adjusted for gestational age at screening. Next, we ranked gestational age-adjusted weight gain into quartiles. We then used multinomial regression ${ }^{38}$ to examine associations of participant characteristics and quartiles of weight gain with glucose tolerance status, which was stratified initially by maternal prepregnancy BMI category. This method calculates the odds of having glucose intolerance, compared with the reference group, NGT. Because we did not find substantial differences in the gestational weight gain-glucose intolerance relationship by BMI after stratification or with the addition of an interaction term $(P=.83)$, we proceeded without stratification.

We included, as covariates, participant characteristics that were of a priori interest or confounded the relationship between weight gain and glucose tolerance status: maternal age, prepregnancy BMI category, race/ethnicity, and history of GDM in a previous pregnancy. Adjustment for other characteristics that included family history of diabetes mellitus, smoking habits, pregravid vigorous activity level, and activity during pregnancy did not result in material changes in the magnitudes of the observed associations between weight gain and outcomes; therefore, we did not include these variables in the final models. Because women with previous GDM are at a higher risk of GDM in a subsequent pregnancy and may modify their weight gain accordingly, we repeated our analysis after excluding women who reported a history of GDM $(n=36)$. 
We additionally fit a separate multinomial regression model to assess the relationship between rate of weight gain with glucose tolerance status. To better understand the interactive and independent effects of rate of weight that was gained in early $(<13$ weeks of gestation) and mid pregnancy ( $\geq 13$ weeks of gestation, but before glycemic screening), we dichotomized the rate of weight gain during each period at the median and created 4 categories: (1) those women with a low rate of gain in both periods, (2) those women with low early pregnancy gain but high gain in mid pregnancy, (3) those women with high early pregnancy gain but low gain in mid pregnancy, and (4) those women with a high rate of gain in both periods. Moreover, to allow for comparison with previously published work, ${ }^{27}$ we calculated each participant's weight gain ratio before glycemic screening (that is, the ratio of actual weight gain to expected gain based on recommendations from the Institute of Medicine over the same time period). ${ }^{25,39}$ We used SAS software (version 9.1; SAS Institute, Cary, NC) to carry out all analyses.

\section{Results}

Among the 1960 participants, mean age was $31.9 \pm 5.1$ (SD) years, and mean prepregnancy BMI was $25.1 \pm 5.4 \mathrm{~kg} / \mathrm{m}^{2}$. One-third of participants were nonwhite, which included $16 \%$ black and $8 \%$ Hispanic women. After adjustment for gestational age at glycemic screening, mean weight gain before screen was $10.2 \pm 4.3 \mathrm{~kg}$ (range, $-9.4 \mathrm{~kg}$ to $29.1 \mathrm{~kg}$ ). Overall, women who were younger, black, obese, or had a previous pregnancy with GDM gained less weight before glycemic screening (Table 1). We found no differences in mean nonfasting screening glucose level or family history of diabetes mellitus across quartiles of gestational weight gain. Mothers who were less active or quit smoking before pregnancy were more likely to gain in the upper quartile of weight before glycemic screening (data not shown).

We identified 1615 women (82\%) with NGT, 174 women (9\%) with GCT $\geq 140 \mathrm{mg} / \mathrm{dL}$ but no high values on the OGTT, 61 women (3\%) with IGT in pregnancy, and 110 women (6\%) with GDM. A large proportion of women (43\%) who eventually were diagnosed with IGT in pregnancy gained in the highest quartile of weight before glycemic screening, in contrast to the relatively equal distribution of NGT mothers across all 4 quartiles of weight gain (Table $1)$.

After adjustment for gestational age at glycemic screening, age, race/ethnicity, history of GDM, and prepregnancy BMI category, gestational weight gain in the highest quartile (12.9-29.1 kg), compared with the lowest $(-9.4 \mathrm{~kg}$ to $7.9 \mathrm{~kg}$ ), was associated with increased risk of IGT in pregnancy (odds ratio [OR], 2.54; 95\% confidence interval [CI], 1.25-5.15), but not GDM (OR, 0.93; 95\% CI, 0.50-1.70; Figure 1). The exclusion of women with a history of GDM in a previous pregnancy did not change the results materially (adjusted OR for IGT in pregnancy, 2.64; 95\% CI, 1.28-5.45, and for GDM, 0.94; 95\% CI, 0.50-1.77). Furthermore, results were essentially unchanged when we analyzed weight gain as the ratio of observed-to-expected gain, as done elsewhere ${ }^{27}$ (data not shown). We found no association between the highest quartile of gestational weight gain and lowest quartile of weight gain among women who had GCT results $\geq 140 \mathrm{mg} / \mathrm{dL}$, but no high values on the OGTT (OR, 1.19; 95\% CI, 0.72-1.97). 
Additional predictors of IGT in pregnancy on multivariate analyses were BMI (OR, 1.89; 95\% CI, 1.04-3.44 for overweight vs normal weight) and history of GDM (OR, 7.68; 95\% CI, 1.46-40.4 for previous GDM vs no history of GDM). Participant characteristics were associated with GDM in the anticipated directions and included race/ethnicity (OR, 2.27; 95\% CI: 1.13-4.57 for Hispanic vs non-Hispanic white), age (OR, 1.08; 95\% CI, 1.03-1.13 per year), BMI (OR, 1.92; 95\% CI, 1.13-3.26 for overweight vs normal weight; OR, 3.92; 95\% CI, 2.22-6.73 for obese vs normal weight), and history of GDM (OR, 80.3; 95\% CI, 19.8-217 for previous GDM vs no history of GDM).

We next explored the relationship of trimester-specific rate of weight gain with IGT in pregnancy and GDM. Median rate of weight that was gained in early pregnancy $(<13$ weeks of gestation) was $0.22 \mathrm{~kg} / \mathrm{wk}$, and median rate of weight that was gained in mid pregnancy ( $\geq 13$ weeks of gestation until glycemic screening) was $0.50 \mathrm{~kg} / \mathrm{wk}$. Compared with women who experienced low weight gains in early and mid pregnancy, those women with high gains in both periods had the greatest risk of IGT in pregnancy (adjusted OR, 2.14; 95\% CI, 1.04-4.42; Table 2). Women whose rate of weight gain was high in the first trimester but low in the second (adjusted OR, 1.40; 95\% CI, 0.65-3.02), or vice versa (adjusted OR, 1.20; $95 \%$ CI, 0.52-2.77) did not have an increased risk of IGT in pregnancy. We observed no association between the timing of weight gain and GDM, although there was a trend toward a greater risk of the development of GDM among mothers with higher rates of weight gain that was isolated to early pregnancy (Table 2 ).

\section{Comment}

In this cohort study that included almost 2000 pregnant women, we found that greater gestational weight gain prior to glycemic screening was associated with an increased risk of IGT in pregnancy. The risk of IGT in pregnancy was most pronounced among women with a high rate of weight gain in both early and mid pregnancy. Adjustment for important predictors of both gestational weight gain and glucose intolerance (namely age, prepregnancy BMI category, race/ethnicity, and history of GDM)strengthened the association between weight gain and IGT in pregnancy. We did not observe an association between weight gain and frank GDM.

Our findings are similar to both prospective cohort and clinical trial work that examined the relationship between gestational weight gain and glucose intolerance, although we found no interaction between prepregnancy BMI and weight gain in relation to IGT in pregnancy. Saldana et $\mathrm{al}^{27}$ found a 2-fold increased risk of IGT in pregnancy among overweight women in the Pregnancy, Infection and Nutrition (PIN) cohort with higher gestational weight gain ratios, but did not observe a similar increase in risk of GDM. A more recent cohort study also revealed a positive relationship between weight gain in excess of Institute of Medicine guidelines and the development of milder states of glucose intolerance, although these findings were limited to Hispanic women with a BMI of $\geq 35 \mathrm{~kg} / \mathrm{m}^{2} .{ }^{40} \mathrm{In}$ a clinical trial among obese Danish women, Wolff et $\mathrm{al}^{28}$ found $20 \%$ reductions in serum insulin and leptin levels at 27 weeks of gestation, along with $8 \%$ reductions in fasting blood glucose at 36 weeks of gestation, in those women who were assigned randomly to a dietary counseling intervention to restrict weight gain to 6-7 kg in pregnancy. The authors, however, saw no 
reduction in the risk of incident GDM, which suggests that changes in weight during pregnancy may have a greater impact on more moderate levels of glucose intolerance, which is consistent with our findings.

The large body of literature that describes associations between weight gain and risk of hyperglycemia in nonpregnant populations provides some insight into the biologic basis of our results. ${ }^{41-43}$ Adipose tissue actively participates in energy homeostasis through alterations in food-intake regulatory signals, including insulin and leptin. ${ }^{44,45}$ There may be a ceiling effect for the body's response to leptin and insulin, above which these hormones have no effect, and individuals will consume more energy, gain excess weight, and experience a persistent state of hyperglycemia despite high circulating hormone levels. 45,46 We speculate that, because women gained more weight in early and mid pregnancy in our cohort, a moderate state of glucose intolerance resulted, which likely reflects a similar set of neuroendocrine changes that occur in the pregnant state. However, we did not find weight gain to be predictive of frank GDM, the most severe form of glucose intolerance in pregnancy. It is unclear whether this finding is related to other, unmeasured factors in our cohort (such as $\beta$-cell exhaustion or pregnancy-specific alterations in insulin resistance ${ }^{47,48}$ ) that predispose women to GDM independent of weight-related changes. Alternatively, mothers who eventually develop GDM may enter pregnancy already in a state of profound insulin resistance ${ }^{49,50}$ that leads to less weight gain over the course of gestation, as detailed in longitudinal studies of the Pima Indian population. ${ }^{51}$ It is possible that the timing or pattern of metabolic changes responsible for frank GDM is different from changes that predict moderate states of glucose intolerance in pregnancy. ${ }^{50,52}$

We also observed that higher levels of gestational weight gain were not associated with GCT results of $\geq 140 \mathrm{mg} / \mathrm{dL}$ but no high values on the OGTT, which may reflect similarities between these participants and women with NGT, particularly with regard to longer term offspring outcomes. ${ }^{8}$ Two recent studies, however, found that mothers who failed glycemic screening but passed the OGTT were at increased risk of pregnancy-induced hypertension, cesarean section delivery because of fetal distress, and 3-month postpartum reductions in insulin sensitivity, compared with those women with NGT in pregnancy. ${ }^{32,33}$ Future work must continue to assess whether these 2 groups share similar predictors and outcomes.

Our study has a number of strengths that include the use of several different measures of gestational weight gain before glycemic screening, adjustment for variation in gestational age at glycemic screen, and inclusion of multiple potential confounding variables. Nevertheless, our findings must be interpreted within the context of the study design. One limitation is the use of self-reported pregravid weight in early pregnancy to calculate our measures of gestational weight gain and BMI category. Because prepregnancy weight was self-reported, it is likely to be underestimated; therefore, gestational weight gain may be overestimated. However, our validation study indicated that ranking of individuals is preserved. ${ }^{29}$ Moreover, we collected prepregnancy weight before women knew their glucose test results, further reduced the possibility of bias. Other limitations include the generalizability of our findings, because our cohort was older and mostly white. Women with abnormal GCT results, but no high values on the OGTT at 26-28 weeks of gestation were not retested routinely in the third trimester of pregnancy, which may have resulted in 
misclassification of glucose tolerance status because of the possibility of later conversion to IGT or GDM. We also had small absolute numbers of women with IGT in pregnancy in our sample that limited our ability to do multivariable-adjusted stratified analyses, which may explain the lack of effect modification by prepregnancy BMI that was found in our study.

In summary, we found that higher weight gain before glycemic screening predicted IGT in pregnancy. Because glucose intolerance less severe than that used to define overt diabetes mellitus is related to clinically important perinatal disorders, ${ }^{8-12}$ strategies to prevent maternal hyperglycemia are critical to the design of interventions to improve outcomes in both mothers and their infants. Our results suggest that reducing pregnancy weight gain may be 1 effective strategy and call for more intervention work to test whether changes in gestational weight gain before second-trimester glycemic screening leads to decreased rates of IGT in pregnancy.

\section{Acknowledgments}

This study was supported by Grants from the National Institutes of Health (HD 34568, HD 64925, HL 68041), Harvard Medical School, and the Harvard Pilgrim Health Care Foundation. Dr Herring was supported by an institutional Ruth L. Kirschstein National Research Service Award (5 T32 HP11001-19) from the Health Resources and Services Administration and the Department of Ambulatory Care and Prevention at Harvard Medical School and Harvard Pilgrim Health Care, Boston, MA.

\section{REFERENCES}

1. American Diabetes Association. Standards of medical care in diabetes - 2008. Diabetes Care. 2008; 31(suppl):S13-S54.

2. American College of Obstetricians and Gynecologists. Gestational diabetes: ACOG Practice Bulletin No.: 30. Obstet Gynecol. 2001; 98:525-538. [PubMed: 11547793]

3. Oken E, Gillman MW. Fetal origins of obesity. Obes Res. 2003; 11:496-506. [PubMed: 12690076]

4. Ogata ES. Perinatal morbidity in offspring of diabetic mothers. Diabetes Rev. 1995; 3:652-657.

5. Sermer M, Naylor CD, Farine D, et al. The Toronto Tri-Hospital Gestational Diabetes project: a preliminary review. Diabetes Care. 1998; 21:B33-B42. [PubMed: 9704225]

6. Gunderson EP, Lewis CE, Tsai AL, et al. A 20-year prospective study of childbearing and incidence of diabetes in young women, controlling for glycemia before conception: the Coronary Artery Risk Development in Young Adults (CARDIA) study. Diabetes. 2007; 56:2990-2996. [PubMed: 17898128]

7. Dabelea D, Pettitt DJ. Intrauterine diabetic environment confers risks for type 2 diabetes mellitus and obesity in the offspring, in addition to genetic susceptibility. J Pediatr Endocrinol Metab. 2001; 14:1085-1091. [PubMed: 11592564]

8. Hillier TA, Pedula KL, Schmidt MM, Mullen JA, Charles MA, Pettitt DJ. Childhood obesity and metabolic imprinting. Diabetes Care. 2007; 30:2287-2292. [PubMed: 17519427]

9. Tallarigo L, Giampietro O, Penno G, Miccoli R, Gregori G, Navalesi R. Relation of glucose tolerance to complications of pregnancy in nondiabetic women. N Engl J Med. 1986; 315:989-992. [PubMed: 3762619]

10. Sermer M, Naylor CD, Gare DJ, et al. Impact of increasing carbohydrate intolerance on maternalfetal outcomes in 3637 women without gestational diabetes. Am J Obstet Gynecol. 1995; 173:146-156. [PubMed: 7631672]

11. Langer O, Brustman L, Anyaegbunam A, Mazze R. The significance of one abnormal glucose tolerance test value on adverse outcome in pregnancy. Am J Obstet Gynecol. 1987; 157:758-763. [PubMed: 3631178]

12. The HAPO Study Cooperative Research Group. Hyperglycemia and adverse pregnancy outcomes. N Engl J Med. 2008; 358:1991-2002. [PubMed: 18463375] 
13. Crowther CA, Hiller JE, Moss JR, et al. Effect of treatment of gestational diabetes on pregnancy outcomes. N Engl J Med. 2005; 352:2477-2486. [PubMed: 15951574]

14. Ferrara A, Kahn HS, Quesenberry C, Riley C, Hedderson MM. An increase in incidence of gestational diabetes mellitus: northern California, 1991-2000. Obstet Gynecol. 2004; 103:526533. [PubMed: 14990417]

15. Chu SY, Callaghan WM, Kim SY, et al. Maternal obesity and risk of gestational diabetes mellitus. Diabetes Care. 2007; 30:2070-2076. [PubMed: 17416786]

16. Solomon CG, Willett WC, Carey VJ, et al. A prospective study of pregravid determinants of gestational diabetes mellitus. JAMA. 1997; 278:1078-1083. [PubMed: 9315766]

17. Hedderson MM, Williams MA, Holt VL, Weiss NS, Ferrara A. Body mass index and weight gain prior to pregnancy and risk of gestational diabetes mellitus. Am J Obstet Gynec. 2008; 198:409, e1-e7. [PubMed: 18068138]

18. Rudra CB, Sorensen TK, Leisenring WM, Dashow E, Williams MA. Weight characteristics and height in relation to risk of gestational diabetes mellitus. Am J Epidemiol. 2007; 165:302-308. [PubMed: 17074967]

19. Villamor E, Cnattingius S. Interpregnancy weight change and risk of adverse pregnancy outcomes: a population-based study. Lancet. 2006; 368:1164-1170. [PubMed: 17011943]

20. Reaven GM. Role of insulin resistance in human disease. Diabetes. 1988; 37:1595-1607. [PubMed: 3056758]

21. Felber, JP.; Acheson, KJ.; Tappy, L. From obesity to diabetes. New York: John Wiley \& Sons; 1993.

22. Rondinone CM. Adipocyte-derived hormones, cytokines, and mediators. Endocrine. 2006; 29:8190. [PubMed: 16622295]

23. Gunderson EP, Sternfeld B, Wellons MF, et al. Childbearing may increase visceral adipose tissue independent of overall increase in body fat. Obesity. 2008; 16:1078-1084. [PubMed: 18356843]

24. Hytten, FE.; Leitch, I. The physiology of pregnancy. 2nd ed. Oxford, UK: Blackwell Scientific Publications; 1971.

25. Institute of Medicine. Nutrition during pregnancy. Washington, DC: National Academy Press; 1990.

26. Dahlgren J. Pregnancy and insulin resistance. Metab Syndr Relat Disord. 2006; 4:149-152. [PubMed: 18370761]

27. Saldana TM, Siega-Riz AM, Adair LS, Suchindran C. The relationship between pregnancy weight gain and glucose tolerance status among black and white women in central North Carolina. Am J Obstet Gynecol. 2006; 195:1629-1635. [PubMed: 16824460]

28. Wolff S, Legarth J, Vangsgaard K, Toubro S, Astrup A. A randomized trial of the effects of dietary counseling on gestational weight gain and glucose metabolism in obese pregnant women. Int $\mathbf{J}$ Obes. 2008; 32:495-501.

29. Oken E, Taveras EM, Kleinman KP, Rich-Edwards JW, Gillman MW. Gestational weight gain and child adiposity at age 3 years. Am J Obstet Gynecol. 2007; 196:322, e1-e8. [PubMed: 17403405]

30. Gillman MW, Rich-Edwards JW, Rifas-Shiman SL, Lieberman ES, Kleinman KP, Lipsultz SE. Maternal age and other predictors of newborn blood pressure. J Pediatr. 2004; 144:240-245. [PubMed: 14760269]

31. World Medical Association declaration of Helsinki. Recommendations guiding physicians in biomedical research involving human subjects. JAMA. 1997; 277:925-926. [PubMed: 9062334]

32. Retnakaran R, Qi Y, Sermer M, Connelly PW, Hanley AJ, Zinman B. Glucose intolerance in pregnancy and future risk of pre-diabetes or diabetes. Diabetes Care. 2008; 31:2026-2031. [PubMed: 18628572]

33. Ju H, Rumbold AR, Willson KJ, Crowther CA. Borderline gestational diabetes mellitus and pregnancy outcomes. BMC Pregnancy Childbirth. 2008; 8:31. [PubMed: 18664297]

34. World Heath Organization. Obesity: preventing and managing the global epidemic: WHO technical report series 894. Geneva, Switzerland: World Health Organization; 2000. 
35. Oken E, Ning Y, Rifas-Shiman SL, Radesky JS, Rich-Edwards JW, Gillman MW. Associations of physical activity and inactivity before and during pregnancy with glucose tolerance. Obstet Gynecol. 2006; 108:1200-1207. [PubMed: 17077243]

36. Stuebe A, Oken E, Rich-Edwards JW, Gillman MW. Associations of diet and physical activity during pregnancy with risk for excessive gestational weight gain. Am J Obstet Gynecol. 2007; 197(suppl):82. [PubMed: 17618768]

37. Radesky JS, Oken E, Rifas-Shiman SL, Kleinman KP, Rich-Edwards JW, Gillman MW. Diet during early pregnancy and development of gestational diabetes. Paediatr Perinat Epidemiol. 2008; 22:47-59. [PubMed: 18173784]

38. Agresti, A. Categorical data analysis. Hoboken, NJ: John Wiley \& Sons; 2002.

39. Siega-Riz AM, Adair LS, Hobel CJ. Institute of Medicine maternal weight gain recommendations and pregnancy outcome in a predominantly Hispanic population. Obstet Gynecol. 1994; 84:565573. [PubMed: 8090394]

40. Tovar A, Must A, Bermudez OI, Hyatt RR, Chasan-Taber L. The impact of gestational weight gain and diet on abnormal glucose tolerance during pregnancy in Hispanic women. Matern Child Health J. 2008 Epub ahead of print.

41. Colditz GA, Willett WC, Rotnitzky A, Manson JE. Weight gain as a risk factor for clinical diabetes mellitus in women. Ann Intern Med. 1995; 122:481-486. [PubMed: 7872581]

42. Ford ES, Williamson DF, Liu S. Weight change and diabetes incidence: findings from a national cohort of US adults. Am J Epidemiol. 1997; 146:214-222. [PubMed: 9247005]

43. Hanson RL, Narayan KM, McCance DR, et al. Rate of weight gain, weight fluctuation, and incidence of NIDDM. Diabetes. 1995; 44:261-266. [PubMed: 7883111]

44. Schwartz MW, Woods SC, Prote D Jr, Seeley RJ, Baskin DJ. Central nervous system control of food intake. Nature. 2000; 404:661-671. [PubMed: 10766253]

45. Schwartz MW, Niswender KD. Adiposity signaling and biological defense against weight gain: absence of protection or central hormone resistance? J Clin Endocrinol Metab. 2004; 84:5889_ 5897. [PubMed: 15579732]

46. Neel JV. Diabetes mellitus: a "thrifty" genotype rendered detrimental by "progress"? Am J Hum Genet. 1962; 14:353-362. [PubMed: 13937884]

47. Kahn SE. The importance of b-cell failure in the development and progression of type 2 diabetes. J Clin Endocrinol Metab. 2001; 86:4047-4058. [PubMed: 11549624]

48. Buchanan TA. Pancreatic b-cell defects in gestational diabetes: implications for the pathogenesis and prevention of type 2 diabetes. J Clin Endocrinol Metab. 2001; 86:989-993. [PubMed: 11238474]

49. Catalano PM, Roman NM, Tyzbir ED, Merritt AO, Driscoll P, Amini SB. Weight gain in women with gestational diabetes. Obstet Gynecol. 1993; 81:523-528. [PubMed: 8459960]

50. Kieffer EC, Tabaei BP, Carman WJ, Nolan GH, Guzman JR, Herman WH. The influence of maternal weight and glucose tolerance on infant birthweight in Latino mother-infant pairs. Am J Public Health. 2006; 96:2201-2208. [PubMed: 17077395]

51. Swinburn BA, Nyomba BL, Sadd MF, et al. Insulin resistance associated with lower rates of weight gain in Pima Indians. J Clin Invest. 1991; 88:168-173. [PubMed: 2056116]

52. Retnakaran R, Zinman B, Connelly PW, Sermer M, Hanley AJ. Impaired glucose tolerance of pregnancy is a heterogeneous metabolic disorder as defined by the glycemic response to the oral glucose tolerance test. Diabetes Care. 2006; 29:57-62. [PubMed: 16373896] 


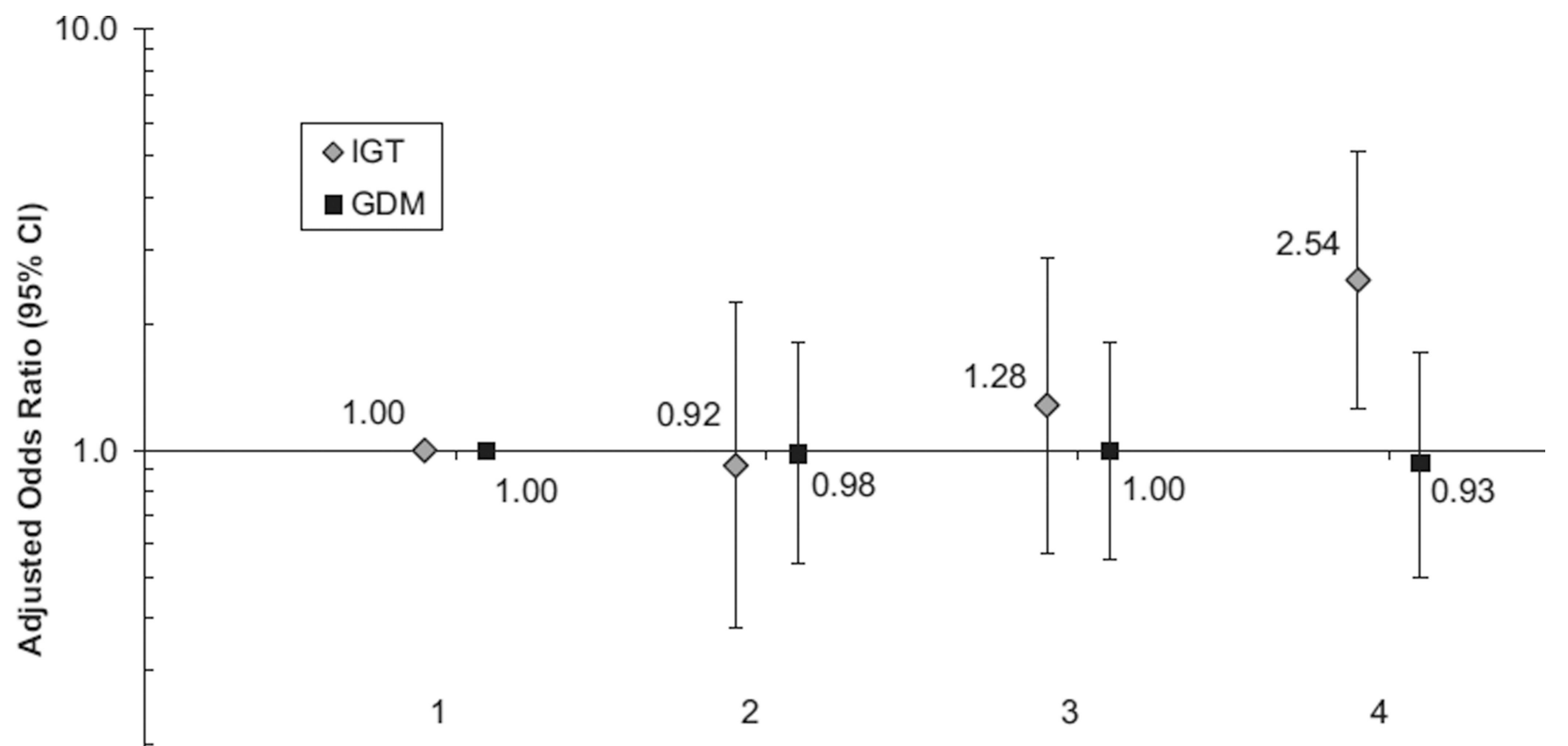

0.1

\section{Quartile of weight gained before glycemic screeing}

FIGURE.

Odds of the development of IGT in pregnancy or GDM by quartile of gestational weight gained before glycemic screening, Project Viva

The estimates were adjusted for gestational age at glycemic screening, age, race/ethnicity, prepregnancy body mass index category, and history of GDM.

$G D M$, gestational diabetes mellitus; IGT, impaired glucose tolerance. 
zon

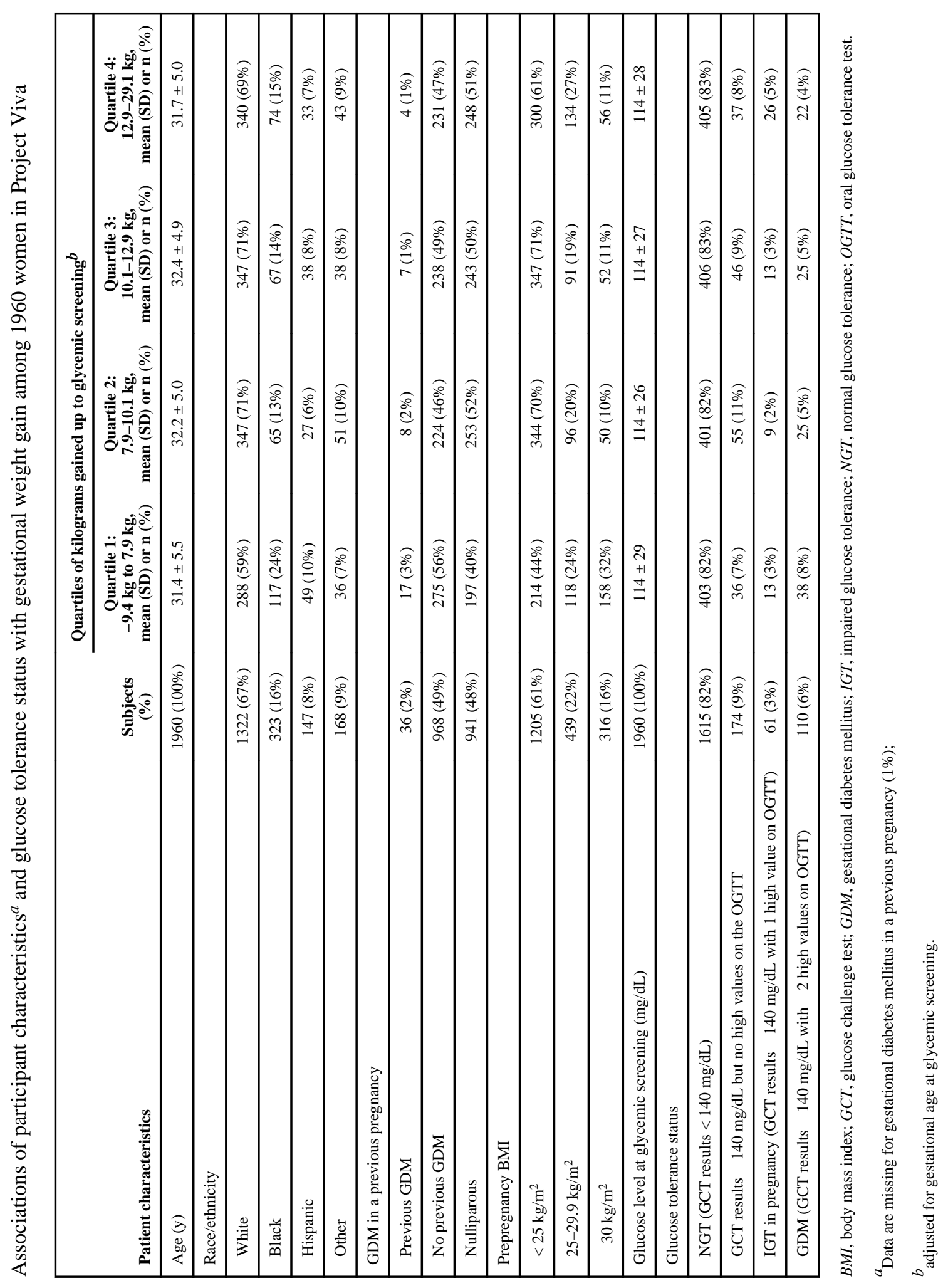

Am J Obstet Gynecol. Author manuscript; available in PMC 2014 June 10. 


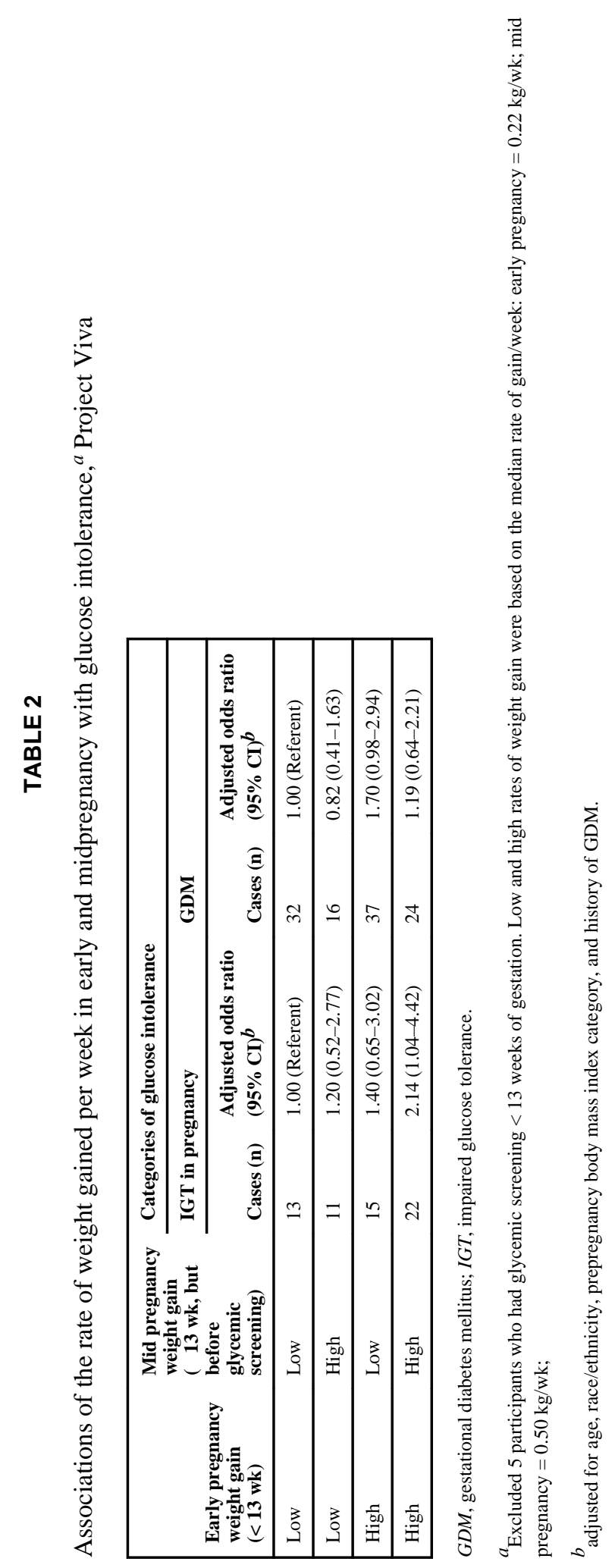

Am J Obstet Gynecol. Author manuscript; available in PMC 2014 June 10. 